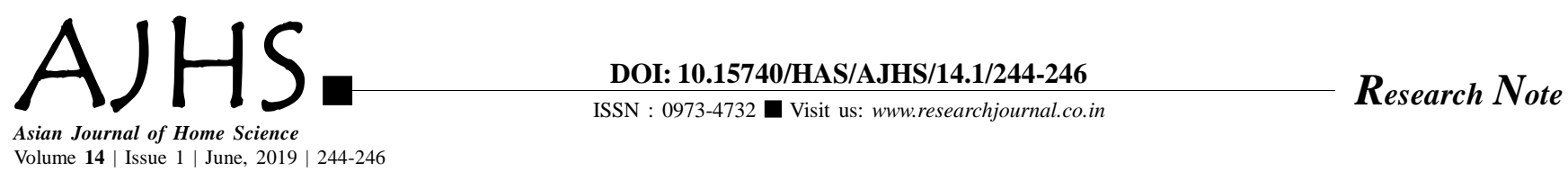

\title{
Developmental delays among young children
}

\section{Deepa and Nasreen Banu}

Received: 02.11.2018; Accepted: 30.05 .2019

See end of the paper for authors' affiliations M. Deepa

Krishi Vigyan Kendra, Guntur (A.P.) India

Email :

deepanarayana@rediffmail.com
ABSTRACT : Study was conducted in Mahabubnagar district with tribal families. Children below two years were selected for the study, stratified and random sampling technique was used to select the villages. Children with developmental delays were identified by using Bayley scale and 30 children below twenty four months were selected after assessing with BSID scale for intervention programme. Results indicated that there was a steep increase in motor delays among children from the beginning of fourth month to till the end of fifth month. Failing of items in motor domain, might be due to poor nutritional status of infants and lack of early stimulation by mothers. Manipulation of objects was poor as these infant were delayed in motor co-ordination, active exploration during play was not seen, because it was observed that infants could not lift head and visually explore the space.

KEY WORDS: Delays among young children

- HOW TO CITE THIS PAPER : Deepa, M. and Banu, Nasreen (2019). Developmental delays among young children. Asian J. Home Sci., 14 (1) : 244-246, DOI: 10.15740/HAS/AJHS/14.1/244-246. Copyright@ 2019: Hind Agri-Horticultural Society. 